DOI: 10.14526/2070-4798-2020-15-1-48-53

\title{
Competitive load influence on athletes' organism in striking kinds of the Olympic combat sports
}

\author{
Oleg G. Epov* \\ Russian State University of Physical Culture, Sport, Youth and Tourism \\ Moscow, Russia \\ ORCID: oooo-ooo3-3820-o991, neg7564@yandex.ru*
}

\begin{abstract}
The process of training highly-qualified athletes is the subject of the research works of many scientists. It is necessary to have correct notion of the differences in periodization of training athletes from the national teams, reserve teams, including sports schools. These differences should be reflected during the training process, while choosing means and methods of training. Otherwise using different means and methods during the training process, before the main start, can lead to a negative result. Materials. Competitive load influence study on athletes' organism in striking kinds of combat sports during training for the main competitions of the yearly cycle. Research methods. Information sources analysis and summarizing, oxygen consumption and carbon dioxide excess determination with the help of gas analyzer Metamax 3B (Cortex, Germany), heart rate with the help of PolarV8oo system, capillary blood analysis with the help of LactateScout; methods of mathematical statistics. Results. Competitive combat use at different stages of the yearly cycle as the training means showed that its realization claims high demands on athletes' organism. During the second round the athletes achieve aerobic maximum and during the third round there is tiredness increase as the reaction to the fulfilled main technicaltactical actions. As a result of it athletes have power and speed-power oriented muscles abilities decrease. It can influence the quality and effectiveness of the fulfilled technical-tactical actions. Conchusion. Maximum intensity training load fulfillment at different stages of the yearly cycle is connected with high demands, which the load claims. There is slow rehabilitation and lactate concentration increase within 3 minutes. The next effort of this exercise should be held no less than in 5 minutes of rest.
\end{abstract}

Keywords: competitive load, striking combat sports, sports training, tiredness, working capacity, micro cycle.

For citation: Oleg G. Epov. Competitive load influence on athletes' organism in striking kinds of the Olympic combat sports. Russian Journal of Physical Education and Sport. 2020; 15(1): 40-44. DOI: 10.14526/2070-4798-2020-15-1-48-53

\section{INTRODUCTION}

The process of training highly-qualified athletes is the subject of many scientists research works [1-7]. It is necessary to have correct notion of the differences in periodization of training athletes from the national teams, reserve teams, including sports schools [6]. The training process periodization has considerable differences. It means that the differences should influence the training process, training means and methods choice. Otherwise using different means and methods during the training process, before the main start, can lead to a negative result. In spite of different points of view and approaches to the training process all specialists want to solve this problem - the highest sport result achievement by an athlete, qualitative and effective training. As a rule, highly-qualified athletes training is realized in terms of the training camps (duration 10-14 days) $[6,8,9,10]$. Usually the means and methods are used, which would model the participation of an athlete in competitions $[1,4,11,12,13]$. If we graphically present the participation of athletes in the International competitions during a yearly cycle of training, we can state that the athletes of striking kinds of combat sports have the following kinds of competitions: boxing - Championship of Europe (CE) and World Championship (WCh), taekwondo WTF (World Taekwondo Federation) - WCh, World Cup (WC), CE (picture 1). Before each competition athletes should take part in the training events and fulfill the training volume of the different orientation loads. The presented periodization characterizes the 
yearly cycle of training planning and differs from the same planning of the nearest reserve athletes long-term training. In this connection the main aim of this research work is to study the influence of competitive load on the organism of athletes in striking kinds of combat sports in terms of direct training for the main competitions of the yearly cycle.

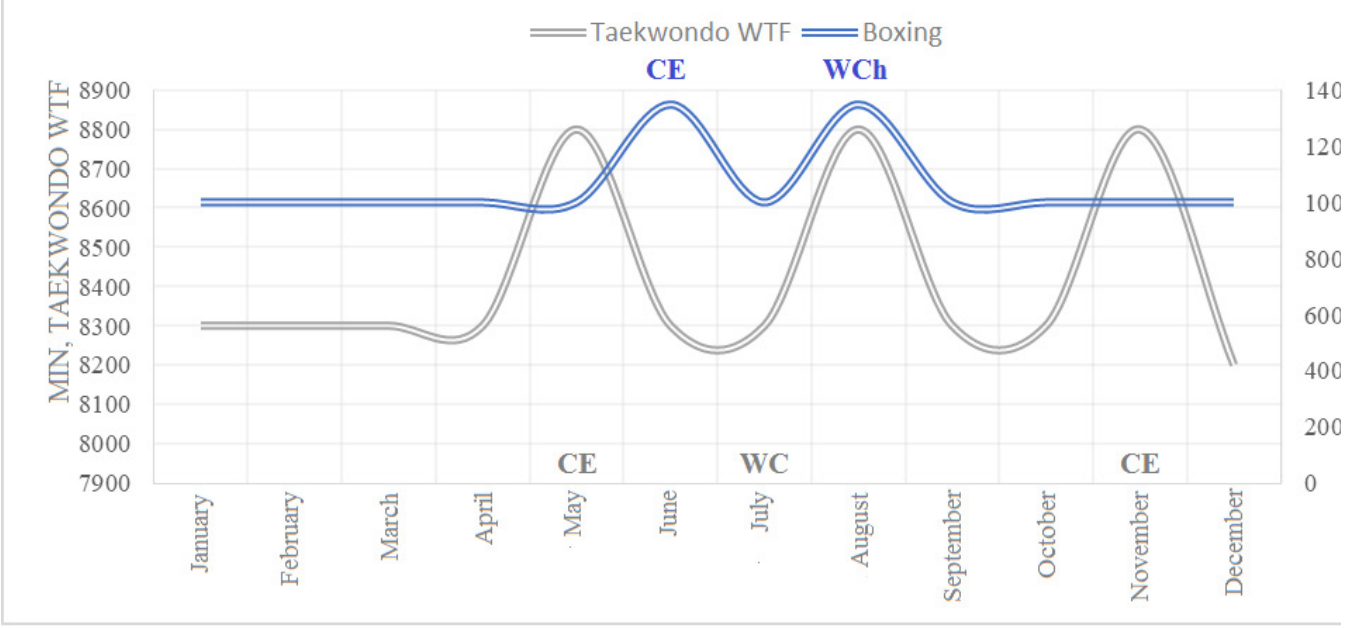

Fig. 1. Periodization of the yearly cycle of training among highly-qualified athletes in boxing and taekwondo WTF

\section{RESEARCH METHODS}

In order to achieve the set aim we held out the research work of athletes' organism urgent reaction to competitive load (combat) fulfillment. For this purpose the group of striking kinds of combat sports athletes (10 athletes) was divided into pairs - 5x2. The main aim was in competitive combat imitation. The average age of athletes $-27,5 \pm 5,96$ years old, weight $-68,4 \pm 8,95 \mathrm{~kg}$. A portable gas analyzer was attached to an athlete in order to define oxygen consumption and carbon dioxideexcess (gas analyzer Metamax 3B, Cortex, Germany). Heart rate (HR) registration was held with the help of HR estimation system PolarV8oo. The athletes had the task to have three rounds (6o seconds each), the interval of rest was 120 seconds. At the beginning of the exercise and at the end of the exercise (sparring) during the $5^{\text {th }}$ minute of rehabilitation we analyzed capillary blood in order to state lactate concentration. For this purpose we used portable device Lactate Scout. Picture 2 and tables 1,2 present research results.

\section{RESEARCH RESULTS}

According to the results of the research we stated that the competitive combat claims great demands on athletes' organism. During the second round athletes achieved their aerobic maximum and then during the third round there was only the increasing tiredness as the reaction to the fulfilled main technical-tactical actions. Since the beginning of the exercise fulfillment till the interval of rest there is a linear pulse, oxygen consumption and minute pulmonary ventilation increase. After the end of the exercise during rehabilitation since the first till the second round athletes had the tendency of pulse, minute pulmonary ventilation, lactate concentration increase and oxygen consumption coefficient decrease. It should be noted that during the second round athletes achieved their maximal oxygen consumption. It is seen in the volume of respiratory coefficient, plateau of oxygen consumption, carbonic acid release, minute pulmonary ventilation. During the third round and after it athletes didn't have changes if the studied indices and it is connected with tiredness increase and the ability to support intensity decrease (picture 2). 


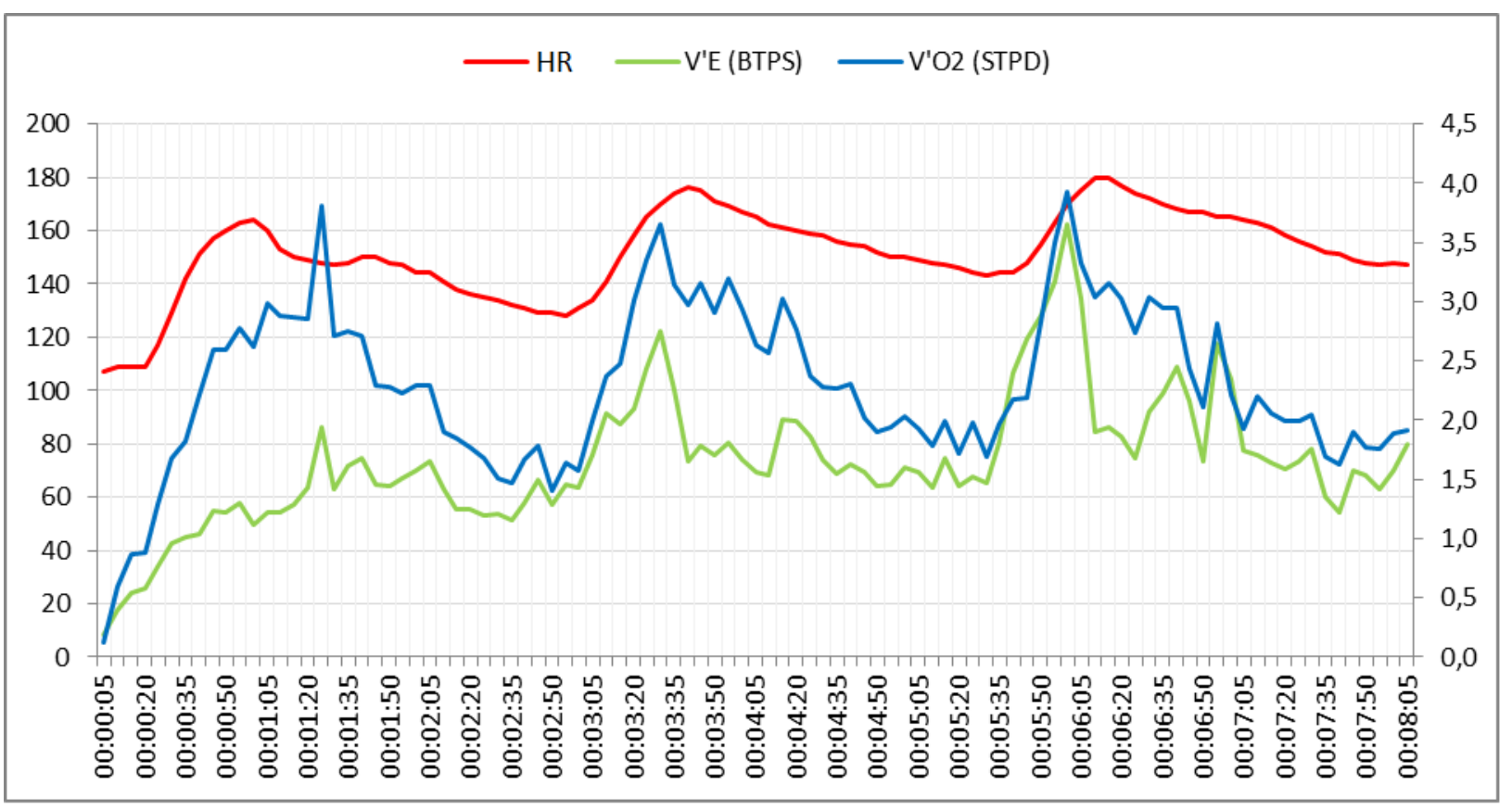

Fig. 2. Urgent reaction of physiological indices to competitive combat by athletes of striking kinds of combat sports

Table 1 - Morphofunctional peculiarities of an organism urgent reaction in the athletes of striking kinds of combat sports. It models competitive combat of the load

\begin{tabular}{|c|c|c|c|c|c|c|}
\hline \multirow{2}{*}{ Load } & \multicolumn{2}{|c|}{ The $1^{\text {st }}$ round } & \multicolumn{2}{c|}{ The $2^{\text {nd }}$ round } & \multicolumn{2}{c|}{ The $3^{\text {rd }}$ round } \\
\cline { 2 - 7 } & $\mathrm{x}$ & $\mathrm{s}$ & $\mathrm{x}$ & $\mathrm{s}$ & $\mathrm{x}$ & $\mathrm{s}$ \\
\hline $\mathrm{HR}, \mathrm{b} / \mathrm{min}$ & 159 & 5,2 & 170 & 5,9 & 173 & 4,8 \\
\hline $\mathrm{VE}, \mathrm{l} / \mathrm{min}$ & 51 & 5,2 & 92 & 17,5 & 99 & 27,1 \\
\hline $\mathrm{VO}_{2} \mathrm{l} / \mathrm{min}$ & 2,4 & 0,4 & 3,2 & 0,2 & 3,0 & 0,5 \\
\hline $\mathrm{VCO}_{2} \mathrm{l} / \mathrm{min}$ & 2,0 & 0,4 & 3,8 & 0,3 & 3,8 & 0,5 \\
\hline $\mathrm{RER}$ & 0,82 & 0,09 & 1,19 & 0,06 & 1,28 & 0,16 \\
\hline \multicolumn{2}{|c|}{} \\
$\mathrm{CUO}_{2}$
\end{tabular}

Table 2 - Morphofunctional peculiarities of an organism urgent reaction in athletes of striking kinds of combat sports in the interval of rest after the modeling competitive combat load fulfillment

\begin{tabular}{|c|c|c|c|c|c|c|}
\hline \multirow{2}{*}{ Rest } & \multicolumn{2}{|c|}{ After the $1^{\text {st }}$ round } & \multicolumn{2}{c|}{ After the $2^{\text {nd }}$ round } & \multicolumn{2}{c|}{ After the $3^{\text {rd }}$ round } \\
\cline { 2 - 7 } & $\mathrm{x}$ & $\mathrm{s}$ & $\mathrm{x}$ & $\mathrm{s}$ & $\mathrm{x}$ & $\mathrm{s}$ \\
\hline $\mathrm{HR}, \mathrm{b} / \mathrm{min}$ & 132 & 2,8 & 145 & 1,9 & 147 & 0,84 \\
\hline $\mathrm{VE}, \mathrm{l} / \mathrm{min}$ & 56 & $5, \mathrm{0}$ & 70 & 6,8 & 71 & 6,04 \\
\hline $\mathrm{VO}_{2} \mathrm{l} / \mathrm{min}$ & 1,6 & 0,2 & 2,0 & 0,2 & 1,9 & 0,08 \\
\hline $\mathrm{VCO}_{2} \mathrm{l} / \mathrm{min}$ & 2,5 & 0,2 & 3,0 & 0,4 & 2,6 & 0,16 \\
\hline $\mathrm{RER}$ & 1,53 & 0,02 & 1,54 & 0,08 & 1,41 & 0,05 \\
\hline $\mathrm{CUO}_{2}$ & 5,0 & 0,3 & 4,3 & 0,5 & 4,4 & 0,28 \\
\hline Lactate $\mathrm{mM} / \mathrm{l}$ & 1,52 & 0,33 & & & 14,2 & 1,7 \\
\hline
\end{tabular}


Thus, this means of training use should be strictly regulated concerning the duration and intensity of rest in a weekly competitive micro cycle while using it as the main training means, especially for the athletes. They have a low level of training. Before and after the modeling competitive load fulfillment we estimated power and speed-power oriented abilities of the front and back part of the hip muscles in order to estimate the influence of motor abilities tiredness, realized with maximum effort. For this purpose the group of athletes (10 people) fulfilled two efforts of knee joint extension with maximum isometric tension sitting at power-estimating complex
BIODEX. The time of the exercise fulfillment was 5 seconds, the interval of rest between the exercises - 30 seconds. The indices of maximum moment of power on repeat, power moment gradient and maximum power on repeat were registered. The enumerated indices characterize speed and power oriented abilities of legs muscles. Table 3 shows that athletes had power moment gradient and maximum power decrease before and after the load fulfillment. It models competitive combat. It finally led to time period increase of maximum motor actions demonstration.

Table 3 - Dynamics of power moment gradient change among athletes of striking kinds of combat sports before and after the modeling competitive combat load fulfillment

\begin{tabular}{|c|c|c|c|}
\hline Indices & Weight, kg & $\begin{array}{c}\text { Power moment gradient } \\
\left(\mathrm{H}^{*} \mathrm{~m} / \mathrm{s}\right)\end{array}$ & $\begin{array}{c}\text { Fmax } \\
(\mathrm{H})\end{array}$ \\
\hline Before the load & $68,4 \pm 8,95$ & $122,9 \pm 53,2$ & $678,3 \pm 32,5$ \\
\hline After the load & $68,1 \pm 8,2$ & $89,0 \pm 38,5$ & $535,6 \pm 42,9$ \\
\hline $\mathrm{p}$ & $>0,5$ & $<0,05$ & $<0,05$ \\
\hline
\end{tabular}

\section{CONCLUSION}

1. Competitive combat use at different stages of the yearly cycle as the training means showed that its realization claims high demands on athletes' organism. During the second round the athletes achieve aerobic maximum and during the third round there is tiredness increase as the reaction to the fulfilled main technical-tactical actions.

2. As a result of tiredness athletes have power and speed-power oriented muscles abilities decrease. It can influence the quality and effectiveness of the fulfilled technical-tactical actions.

3. Maximum intensity training load fulfillment at different stages of the yearly cycle is connected with high demands, which the load claims. There is slow rehabilitation and lactate concentration increase within 3 minutes. The next effort of this exercise should be held no less than in 5 minutes of rest.

\section{REFERENCES}

1 Akopyan A.O. Some aspects of scientific-methodical support (SMS) organization in the Olympic kinds of single combats at the stages of training for Olympiad 2016. Vserossijskaya nauchno-prakticheskaya konferenciya [AllRussian scientific-practical conference]. Moscow. 2013: 92-96 [In Russ.].

2 Seluyanov V.N. Control over physical readiness in sports adaptology. Teoriya I prakitka fizicheskoj kul'tury = Theory and practice of physical culture. 2008; 5: 36-38, 55-56 [In Russ., In Engl.].

3 Levshin I. V., Pavlov I.D., Bolshova E.V. Physiological substantiation of integral estimation of taekwondists' functional state and working capacity. Lechebnaya fizkul'tura I sportivnaya medicina. 2015; 1: 19-25 [In Russ.].

$$
4 \text { Maximov D. V., Seluyanov }
$$

V.N., Tabakov S.E. Fizicheskaya podgotovka edinoborstsev (sambo I dzyudo). Teoretikoprakticheskie rekomendacii [Physical training of combatants (sambo and judo). Theoretical-practical recommendations]. TVT Devision. 2011: 160 [In Russ.].

5 Popov D.V. Factors, which restrict aerobic working capacity at the level of the separate 
muscle among people with different training level. Candidate's thesis. Moscow. 2007: 25.

6 Abalyan A.G. The peculiarities of scientific-methodical support of training organization among sports national teams of the Russian Federation. Teoriya I praktika fizicheskoj kul'tury I sporta: trener: zhurnal v zhurnale. 2011; 11: 66-70 [In Russ.].

7 Svishchev I.D. Novyj sposob razvitiya sily myshe nog I tulovicha u bortsov: metodicheskie rekomendacii [A new way of legs muscles and body development among wrestlers : methodical recommendations]. Moscow: PrintCenter. 2011: 14.

8 Epov O.G. Conjugate training for legs muscles in microcycle of training for com petitions among athletes of high qualification intaekwondo WTF. Pedagogiko-psihologicheskie I medico-biologicheskie problemy fizicheskoj kul'tury I sporta = The Russian Journal of Physical Education and Sport. 2018; 13(2): 79-86. DOI 10.14526/02_2018_311. Epov O.G. [In Russ., In Engl.].

9 Epov O.G., Meshcheryakov A.V. Criteria of physical fitness level evaluation at representatives of different shock types of the Olympic single combats. Pedagogiko- psihologicheskie I medico-biologicheskie problemy fizicheskoj kultury I sporta = Russian Journal of Physical Education and Sport. 2019; 14(1): 74-80. DOI 10.14526/2070-4798-2019-14-1-74-80 [In Russ., In Engl.]

10 Baron B., Moullan F., Deruelle F., Noakes T.D. The role of emotions on pacing strategies and performance in middle and long duration sport events. British Journal of Sports Medicine. 2009; 19: 220-238. DOI: 10.1136/bjsm.2009.059964.

11 Cerin E., Barnett A. A processual analysis of basic emotions and sources of concerns as they are lived before and after a competition. Psychology of Sport and Exercise. 2006; 7: 287307. DOI: 10.1016/j.psychsport.2005.07.002.

12 Hill D.M., Hanton S., Fleming S., Matthews N. A re-examination of choking in sport. European Journal of Sports Science. 2009; 2: 142157. DOI: $10.1080 / 17461390902818278$.

13 Lucas S.E., Ansona J.G., Palmera C.D., Hellemans I.J., Cottera J.D. The impact of 100 hours of exercise and sleep deprivation on cognitive function and physical capacities. Journal of Sports Sciences. 2009; 27: 719-728. DOI: 10.1080/02640410902798167.

\section{Submitted: 15.02.2020}

Oleg G. Epov - Candidate of Pedagogics, Professor, Russian State University of Physical Culture, Sport, Youth and Tourism, 105122, Russia, Moscow, Sirenevyj blvr., House 4, e-mail:neg7564@yandex.ru 